\title{
Quantitative Ultrasound Methods to Assess Bone Mineral Status in Children: Technical Characteristics, Performance, and Clinical Application
}

\author{
GIAMPIERO I. BARONCELLI \\ Department of Pediatrics, "S. Chiara” University-Hospital, Pisa 56126, Italy
}

\begin{abstract}
Measurement of bone mineral status may be a useful tool in identifying the children who could be exposed to an increased risk of osteoporosis in adulthood. Dual energy x-ray absorptiometry and peripheral quantitative computed tomography may be used to this purpose, but the exposure to ionizing radiation is a limiting factor for preventive studies in large populations of children. In the last years, quantitative ultrasound (QUS) methods have been developed to assess bone mineral status in some peripheral skeletal sites such as calcaneus, phalanges of the hand, and tibia. QUS techniques are safe, easy to use, radiation-free, and devices are portable, so that they are particularly indicated to assess bone mineral status in children. This review will concentrate on the main methodological principles of ultrasounds and the QUS variables derived from their application to bone tissue, technical differences and performance of QUS methods, factors influencing QUS measurements, normative data and results obtained in children with disturbances of growth or affected by disorders of bone and mineral metabolism, including the assessment of fracture risk, and comparison among QUS, dual energy x-ray absorptiometry, and peripheral quantitative computed tomography methods. (Pediatr Res 63: 220-228, 2008)
\end{abstract}

$I^{n}$ the last years, the demand for measurement of bone mineral status to identify children who could be exposed to an increased risk of osteoporosis in adulthood is rapidly increased. Several disorders, by various mechanisms, may be associated with a reduced bone mineral status; in particular, patients with chronic or genetic diseases, malignancies, acute or chronic disabilities caused by neuromuscular disorders, and patients receiving prolonged glucocorticoid treatment are at risk of fractures by minimal trauma caused by a severe reduction in bone mineral status (1).

Moreover, there is a growing demand for assessing the effects of some environmental factors on bone health, such as dietary habits and various degrees of physical activity by using radiationfree techniques.

\section{DENSITOMETRIC TECHNIQUES FOR ESTIMATING BONE MINERAL STATUS IN CHILDREN}

Some densitometric techniques to assess bone mineral status developed for adults have been adapted for the use in children. Dual energy x-ray absorptiometry (DXA) is the most commonly used technique for bone mineral status assessment worldwide. The main advantages of DXA are its wide availability and short scanning times, but the subject is exposed to ionized radiation that varies according to the machinery and the examined skeletal site; anyway, radiation dose to patient from DXA is minimal $(0.08-4.6 \mu \mathrm{Sv}$ and $6.7-31 \mu \mathrm{Sv}$ for pencil beam and fan beam methods, respectively) compared with that given by many other investigations involving ionizing radiation (2). Nevertheless, an important shortcoming of DXA is that it measures bone in two dimensions providing only an estimation of bone density. Indeed, DXA measures an integral areal density that is calculated as bone mineral content/bone surface area ratio, usually defined as bone mineral density (BMD area or more simply BMD); thus, in growing children, BMD is closely related to the large biologic variation in BMD measurements mainly because of the age-related changes in bone geometry. A partial correction of this confounding factor may be obtained by calculating the apparent bone sizes by some mathematical formulas to obtain a more accurate densitometric variable, defined as bone mineral adjusted density or volumetric BMD (3-6). However, there is no agreement among the scientists with the use of this method to correct BMD values.

Quantitative computed tomography (QCT) has some important advantages compared with DXA because it provides a three-dimensional assessment of the structural and geometric properties of the examined bone, and a separation of cortical and trabecular bone (6). A major disadvantage is the highradiation dose $(50-100 \mu \mathrm{Sv})$, making it unsuitable for use in the pediatric population (5). Peripheral QCT (pQCT) permits 

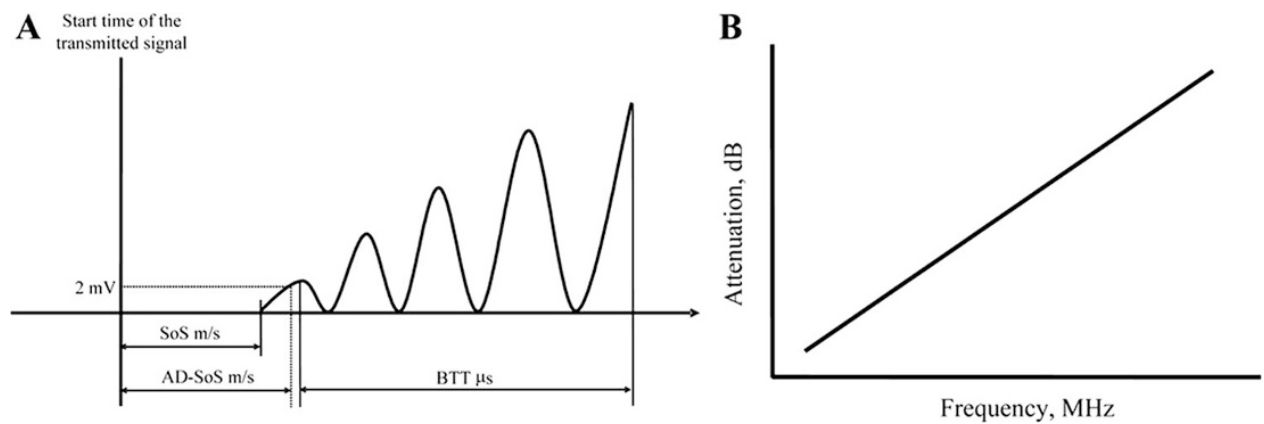

Figure 1. Methods to calculate some QUS variables related to ultrasound velocity $(A)$ and ultrasound attenuation $(B)$. SoS is calculated as the ratio of the distance traveled by the impulse (the distance between the probes) and the time taken by the signal to travel that distance. AD-SoS reflects the amplitude-dependent velocity with a threshold of $2 \mathrm{mV}$; BTT is the interval between the time when the first peak of the signal received reaches its maximum level and the time measured whether no bone but only soft tissue should be present between the two transducers; BUA is the slope of the regression line of attenuation against frequency, according to the formula $\mathrm{BUA}=\Delta \mathrm{db} / \Delta \mathrm{MHz}$

a three-dimensional analysis of some appendicular bones, such as radius, ulna, and femur, by using a lower radiation dose $(<2 \mu \mathrm{Sv})$ when compared with axial QCT (5), but it is not currently used for clinical purposes in children.

Quantitative ultrasound (QUS) is a relatively recent and noninvasive method of estimating bone mineral status at peripheral skeleton. In addition to bone density, QUS methods provide some structural information, which may be important in determining the fracture risk (7-9). QUS technique is safe, easy to use, and cost-effective; the devices are portable, only few minutes are needed to perform the measurements, and it is radiation-free. These characteristics are particularly indicated to assess bone mineral status in children.

Despite its proven advantages, the use of QUS remains controversial. In fact, there is a general scepticism about the use of QUS techniques for the assessment of bone mineral status because of poor knowledge on the physical mechanisms of ultrasounds in assessing bone characteristics, technological diversity among QUS devices, use of different QUS variables to estimate bone mineral status, and difficulty to compare the results obtained by QUS devices with those acquired by the $\mathrm{x}$-ray-based densitometric techniques. Recent studies have clarified most of these aspects leading to clinical application of QUS methods in a large number of disorders.

\section{ULTRASOUND CHARACTERIZATION OF BONE TISSUE AND DERIVED VARIABLES}

Ultrasound is a traveling mechanical vibration and the mechanical and structural properties of the medium progressively alter the shape, intensity, and speed of the propagating wave (8). Based on this principle, the velocity of transmission and the amplitude of the ultrasound signal are influenced by the bone tissue, reflecting its density, architecture, and elasticity (7-10). However, ultrasound velocity measurement does not selectively assess each component of bone tissue influencing ultrasound transmission through bone; indeed, ultrasound velocity is influenced by structural bone variables that are also dependent on bone density (11). Studies in vitro demonstrated that ultrasound velocity was related more strictly to bone density than to bone elasticity $(12,13)$. Ultrasound velocity is related to specific biomechanical properties of bone, such as elastic modulus (a measure of resistance to deformation) and compressive strength (bone's load-carrying capacity) (7-10).

The attenuation of an ultrasound wave through a medium occurs by a reduction in its amplitude and results in a loss of acoustic energy. The predominant attenuation mechanism in cancellous bone is scattering (redistribution of the energy in one or more directions), whereas absorption (dissipation of the energy in the medium by a conversion to heat) predominates in cortical bone (8). A main difference between ultrasound velocity and ultrasound attenuation is that, in contrast to velocity, no theoretical relationship has been established between attenuation of the signal and mechanical properties of cancellous bone $(8,10)$.
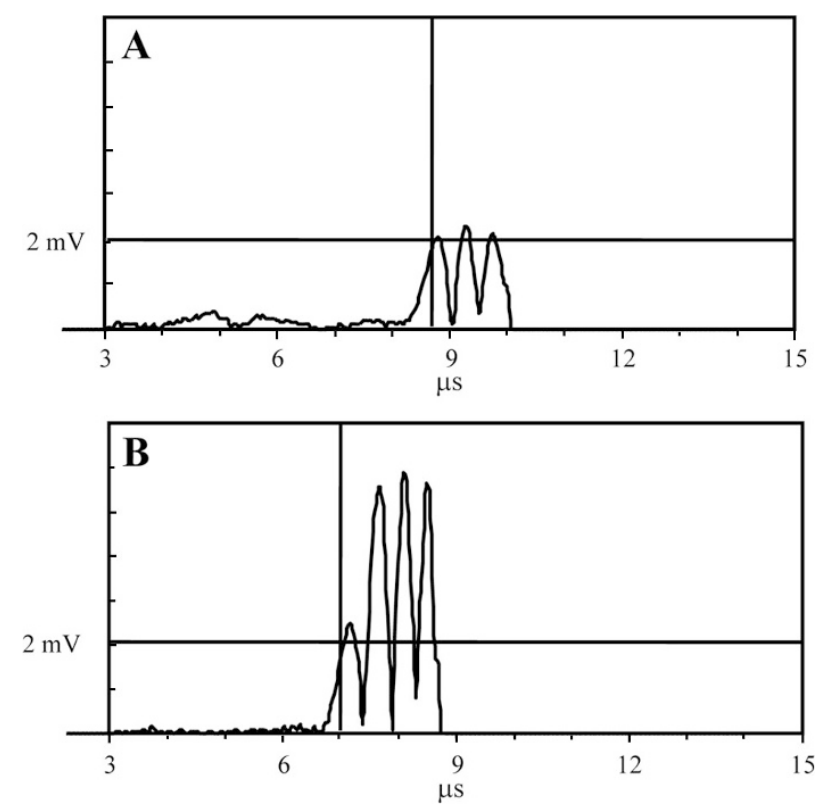

Figure 2. The graphic trace measured at proximal phalanx of the index finger (assessed by QUS device DBM Sonic, IGEA, Carpi, Italy) in a 10.7-y-old boy receiving long-term glucocorticoid treatment for severe asthma $(A)$ and in a healthy boy with the same age for comparison $(B)$. Note the different morphology of the ultrasound signal in the patient compared with that of the healthy child showing reduced amplitude and number of the peaks with a delayed time in reaching the first peak of $2 \mathrm{mV}$, associated with a lower AD-SoS value $(1789 \mathrm{~m} / \mathrm{s}$ and $1925 \mathrm{~m} / \mathrm{s}$, respectively) (see legend of Fig. 1 for technical details, personal cases). 
Two main variables can be measured by QUS devices, which derive from velocity or attenuation of the ultrasound waves through the bone tissue. In Figure 1 are schematized the main methods for calculating the QUS variables related to velocity, by the analysis of the ultrasound signal, and the attenuation as a function of frequency. The QUS variables reflecting ultrasound velocity inside the bone, expressed as meter per second, are known as speed of sound (SoS), that is a pure parameter of velocity independent of ultrasound wave attenuation $(7,8,10,14)$, and amplitude-dependent SoS (AD$\mathrm{SoS})$ that is partly amplitude-dependent $(14,15)$. AD-SoS derives from the measurement of the interval between the start time of the transmitted signal and the time the signal received reaches the predetermined minimum amplitude value of $2 \mathrm{mV}$ for the first time $(14,15)$. A variable more recently got ready is the bone transmission time (BTT), expressed as microsecond, that reflects the bone properties independent of the confounding effect of soft tissue (see below) $(14,16)$. SoS is a variable usually measured by QUS methods applied to the heel, radius, tibia, and patella, whereas AD-SoS and BTT are the main variables measured by the phalangeal QUS device.

The most common variable reflecting ultrasound attenuation through bone is known as broadband ultrasound attenuation (BUA), that is a measure of the frequency dependence of the attenuation of the signal, and is expressed as $\mathrm{dB} / \mathrm{MHz}$. BUA is approximately linear and is expressed on a logarithmic over the range $0.1-1 \mathrm{MHz}$. The increase of BUA as a function of the frequency is estimated by comparing the amplitude spectrum for a reference material with that of the measured sample $(7,8,10)$. This parameter is commonly assessed by calcaneal QUS devices.

To improve precision some calcaneal QUS devices provide additional ultrasound variables derived from the mathematical combination of both SoS and BUA, defined as stiffness index $[(0.67 \times \mathrm{BUA})+(0.28 \times \mathrm{SoS})-420](17,18)$ and quantitative ultrasound index $[0.41 \times(\mathrm{BUA}+\mathrm{SoS})-571](19)$, expressed as percent. However, the clinical usefulness of these QUS variables should be validated in children.

Phalangeal QUS device, by the analysis of the changes in the ultrasound graphic trace occurring during the crossing inside the finger, may provide information on the amplitude and the number of peaks of the ultrasound wave that could be useful in clinical setting, as found in adults $(20,21)$. Currently, very few data are available in children; Figure 2 shows this aspect.

\section{MAIN TECHNICAL CHARACTERISTICS OF QUS METHODS}

The majority of QUS devices are appointed to only one skeletal site, such as proximal phalanges of the hand, heel, and tibia, but a multisite QUS device able to measure (by using different probes) one or more skeletal sites, such as tibia, radius, third phalanx of the hand, and fifth metatarsal, is also available on the market. In children, the tibia (midshaft) and radius (distal third) are the skeletal sites usually measured by the multisite QUS device.

QUS devices differ among them for technical characteristics, including frequency of emitted ultrasounds, pathways of ultrasound transmission inside the bone, skeletal site and regionof-interest (ROI) measured, bone components examined, and QUS variables assessed to estimate bone mineral status and their precision (Table 1, 22,23).

QUS devices generate pulsed acoustic waves with a range of center frequency between $500 \mathrm{kHz}$ and $1.25 \mathrm{MHz}$, according to the manufacturer, which is considerably lower than the frequencies commonly used in echography.

The transmission of the ultrasound waves in calcaneal QUS devices occurs by a thermally controlled water bath in which the foot must be placed or by coupling gel (water- or oilbased), whereas others are gel-free (dry system) by using isopropyl or ethylic alcohol (70\%). Phalangeal and multisite

Table 1. Site of measurement and ROI, bone components, pathways of ultrasound transmission, and QUS variables and their precision of the main QUS methods

\begin{tabular}{|c|c|c|c|c|c|c|}
\hline \multirow{2}{*}{$\begin{array}{c}\text { Skeletal site of } \\
\text { measurement }\end{array}$} & \multirow[b]{2}{*}{ ROI } & \multirow[b]{2}{*}{ Bone components at the ROI } & \multirow{2}{*}{$\begin{array}{l}\text { Pathways of ultrasound } \\
\text { transmission inside the bone }\end{array}$} & \multicolumn{3}{|c|}{ QUS measurements } \\
\hline & & & & Variable & $\mathrm{CV} \%$ & $\mathrm{sCV} \%$ \\
\hline \multirow[t]{3}{*}{ Heel } & \multirow[t]{3}{*}{ Midcalcaneus* } & \multirow{3}{*}{$\begin{array}{l}\text { Trabecular bone }(>90 \%) \text { with a thin } \\
\text { cortical shell }\end{array}$} & \multirow[t]{3}{*}{ Transverse } & $\operatorname{SoS}$ & $0.2-3.9$ & \multirow[t]{3}{*}{-} \\
\hline & & & & BUA & $2.7-7.0$ & \\
\hline & & & & SI/QUI & $1.9-2.7$ & \\
\hline Patella $\dagger$ & $\begin{array}{l}\text { Maximal transverse } \\
\text { diameter }\end{array}$ & $\begin{array}{l}\text { Trabecular bone with a thin cortical } \\
\text { shell }\end{array}$ & Transverse & SoS & $0.5-2.5$ & - \\
\hline \multirow{2}{*}{$\begin{array}{l}\text { Proximal phalanges } \\
\text { of the hand (digit } \\
\text { II-V) }\end{array}$} & \multirow{2}{*}{$\begin{array}{l}\text { Distal end of diaphysis } \\
\text { below the condyles }\end{array}$} & Cortical bone $(\sim 60 \%)$ & \multirow{2}{*}{ Transverse } & AD-SoS & $0.3-0.9$ & $1.7 \ddagger$ \\
\hline & & $\begin{array}{l}\text { Trabecular bone }(\sim 40 \%) \\
\text { Small medullary canal }\end{array}$ & & BTT & $1.0-3.5$ & $0.4 \S$ \\
\hline Radius & Distal third & Cortical bone $(>95 \%)$ & Axial & SoS & $0.4-0.9$ & - \\
\hline Thumb & $\begin{array}{l}\text { Ultradistal end of } \\
\text { diaphysis }\end{array}$ & $\begin{array}{l}\text { Trabecular bone with a thin cortical } \\
\text { shell }\end{array}$ & Transverse & SoS & 0.6 & - \\
\hline Tibia & Midshaft & Cortical bone $(\sim 100 \%)$ & Axial & SoS & $0.3-1.0$ & $3.3 \div$ \\
\hline
\end{tabular}

$\mathrm{CV}$ indicates coefficient of variation $=([\mathrm{SD} /$ mean $] \times 100) ; \mathrm{sCV}$, standardized coefficient of variation; SI, stiffness index $(17,18)$; QUI, quantitative ultrasound index (19).

* The location and size of the ROI vary according to the device.

$\dagger$ Currently not available on the market.

$\$([\mathrm{SD} /$ mean $] \times 100) /($ dynamic range/mean $)(22,23)$.

$\S$ The precision error of BTT was standardized to AD-SoS as reference parameter by some calculations (14). 
QUS devices use coupling gel for the transmission of the ultrasounds to the examined skeletal site.

The pathways of ultrasound transmission inside the bone are determined by two main factors: the position of the transducers (one or more ultrasound signal transmitters and one or more ultrasound receivers) with respect to the examined bone, which depends on the QUS method, and the bone components at the ROI. In Figure 3 are schematized the main QUS methods and the skeletal sites usually assessed in clinical practice. Technology of phalangeal and calcaneal QUS devices is based on the principle of the transverse ultrasound transmission (ultrasound transmitters and receivers are placed on opposite sides of the examined bone with a variable distance among them according to the bone plus soft tissues thickness). Multisite QUS device equipped with the probe for midtibia and distal third of radius is based on the axial transmission along the cortical bone (the probe contains a set of two transmitters and two receivers positioned on one side of the bone, at a fixed distance, such that SoS that travel along the length of the examined bones is measured using the "critical angle" concept); the velocity of an ultrasound wave traveling through a few centimeters of bone and parallel to its axis within the outer $2-6 \mathrm{~mm}$ is measured (24).

Precision of QUS variables in children is reported to be better for SoS than for BUA (25-27), as found in adults (8), and it is similar to that reported for DXA (28-30). Foot positioning is a main cause of measurement imprecision in BUA caused by regional variation in trabecular bone structure (31), and this may be a limiting factor in longitudinal measurements.

\section{EFFECT OF BONE SIZE AND GEOMETRY, SOFT TISSUE THICKNESS, AND ANTHROPOMETRIC FINDINGS ON QUS VARIABLES}

Bone size may affect the measurement of QUS variables, mainly at the heel $(25,32,33)$. In growing children, it has been estimated that only $6 \%$ of AD-SoS values may be related to finger width, indicating that bone width is only a minor confounder on $\mathrm{AD}-\mathrm{SoS}$ measurements at the proximal phalanges of the hand (22). Tibial length, which partly reflects its size, is negatively correlated with SoS values (34).

A close relation between body height and bone geometry exists because the biomechanical forces applied to the skeleton depend on body height (35). It has been demonstrated that heel width (bone plus soft tissue), a parameter partly reflecting the geometry of the calcaneus, was correlated negatively with SoS and positively with BUA (33). Human phalangeal investigations showed that AD-SoS was significantly correlated with cortical thickness and cortical area, but not by crosssectional area of the medullary canal (36-38). In women, tibial SoS (midshaft) was correlated with cortical thickness (39), whereas radial SoS (distal third) was correlated with both cortical thickness and area (40); no data are available for children.

Some evidences indicate that the thickness of the surrounding soft tissues at the heel (41), proximal phalanges of the hand (36), and tibia or radius (42) may influence the QUS variables. A practical way of minimizing the measurement
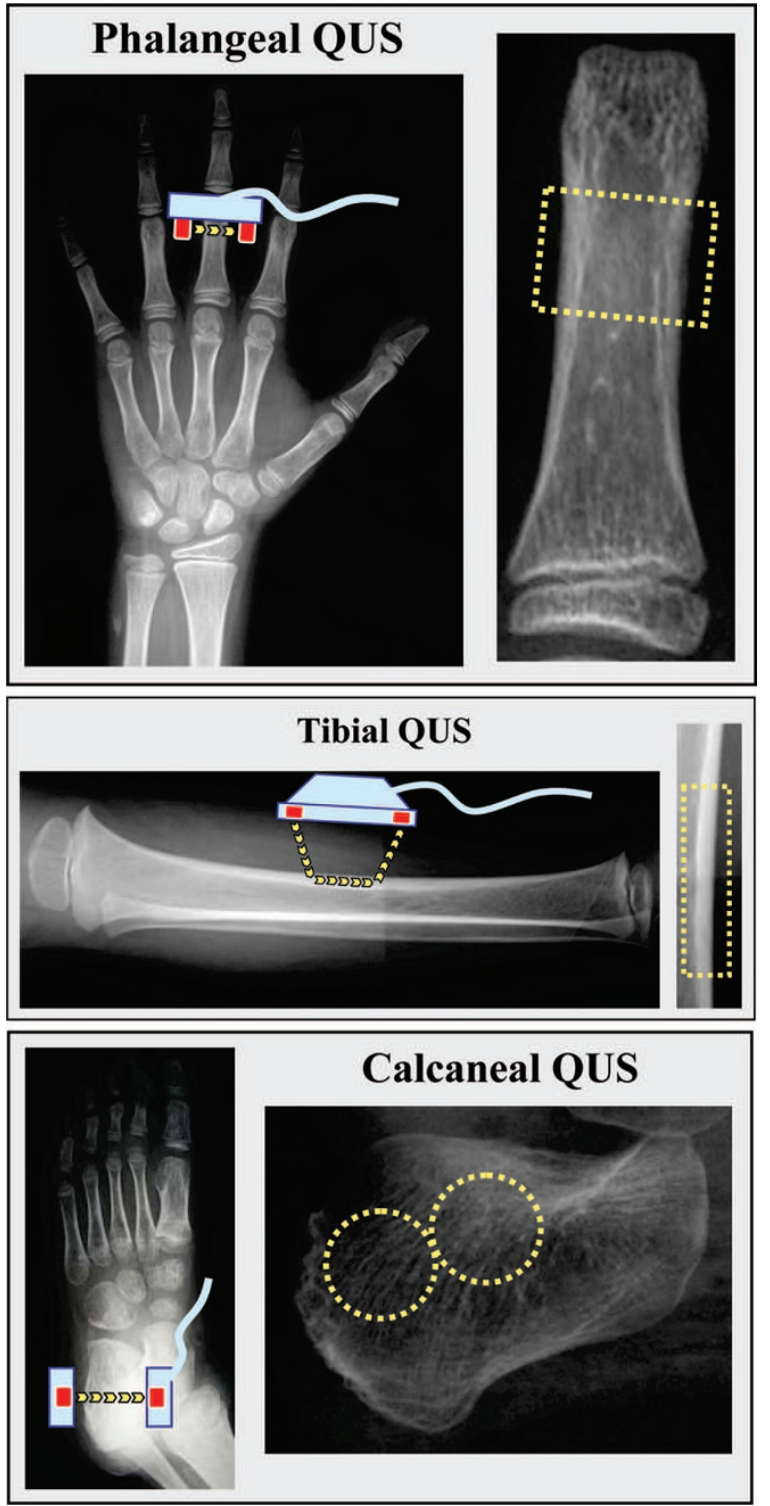

Figure 3. Schematic representation of QUS devices currently used to assess bone mineral status in children. X-ray films are used to represent the skeletal site of measurement, and the approximate ROI is depicted on the right side for each device. In light blue is the probe(s) and in red are the transducers; the yellow arrows indicate the principal pathways of the ultrasound waves from the emitter transducer(s) to the receiving transducer(s). The proportion of devices and transducers, as well as the dimensions of the ROI, with respect to the examined bone is not kept for graphic reasons. The yellow rectangle approximately indicates the ROI for phalangeal (distal end of diaphysis of the first phalanx of the hand; the last four fingers of the hand are measured and the result is the mean of the four fingers; DBM Sonic, IGEA, Carpi, Italy) and tibial (midshaft; Sunlight Omnisense, Tel Aviv, Israel) QUS devices. The yellow rings indicate the approximate locations of the manufacturer's ROI for two calcaneal QUS devices; the surface area of the ROI may be different among the calcaneal QUS devices according to the manufacturer. Note the different bone composition at the ROI for phalangeal, tibial, and calcaneal QUS devices (see Table 1 for more details).

error could be to perform an adequate correction for the overlying soft tissue. Phalangeal QUS device is able to measure the reference SoS of the subject's soft tissue by applying the probes to the soft tissue area of the first interdigital space. The value is then automatically used by the device when measuring AD-SoS in the phalanx to take account, at least in 
part, of soft tissue interference (22). Nevertheless, BTT variable is largely independent of soft tissue bias, and so it represents an accurate parameter to assess bone mineral status at phalanges of the hand (14).

Anthropometric findings, including pubertal stages, are additional factors influencing QUS variables assessed at the heel $(18,25,26,43)$, proximal phalanges of the hand $(16,22,44,45)$, and tibia or radius $(46,47)$, indicating that skeletal growth and gender-dependent bone maturation are important determinants of QUS measurements; so, the auxologic parameters should be taken into consideration in QUS measurements and clinical interpretation of results.

QUS variables are usually measured at only one side that is the nondominant hand, left or right tibia and radius, and right heel. In healthy children, no difference in QUS variables between right and left side has been reported for proximal phalanges of the hand (22) and midshaft tibia (23), but con- trasting results are reported for the heel, likely because of anatomical differences related to structural heterogeneity of calcaneus $(48,49)$.

\section{NORMATIVE DATA FOR QUS VARIABLES}

Some studies have reported normative data for QUS variables measured at the heel (available only for children above $6 \mathrm{y})(25,26,50-52)$, proximal phalanges of the hand $(14,16,53)$, tibia (midshaft) (46,54), and radius (distal third) (46). A large reference database according to the main anthropometric findings, including pubertal stages and body mass index, expressed as centiles, has been recently provided for phalangeal QUS (Fig. 4) (16). Pediatric reference values for calcaneal (51) and tibial and radial (46) QUS, expressed as mean and SD, are depicted in Figures 5 and 6, respectively.

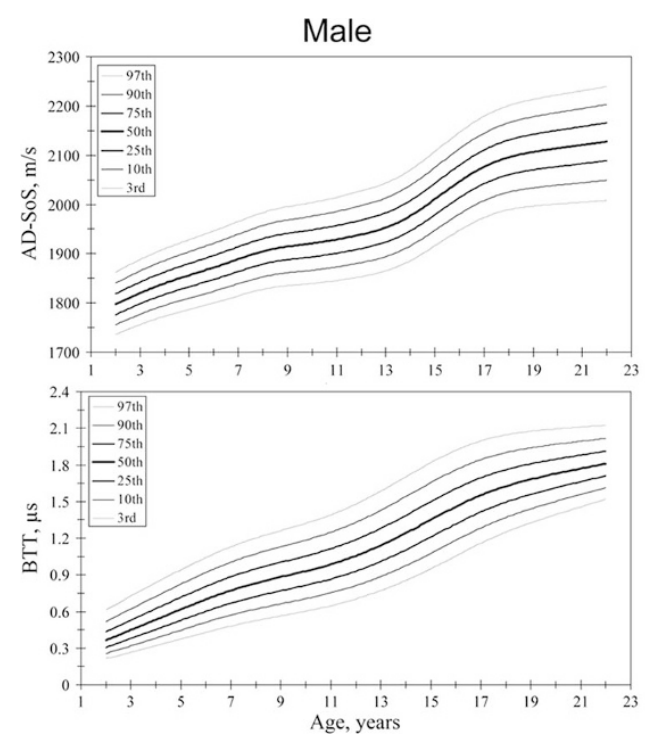

Male
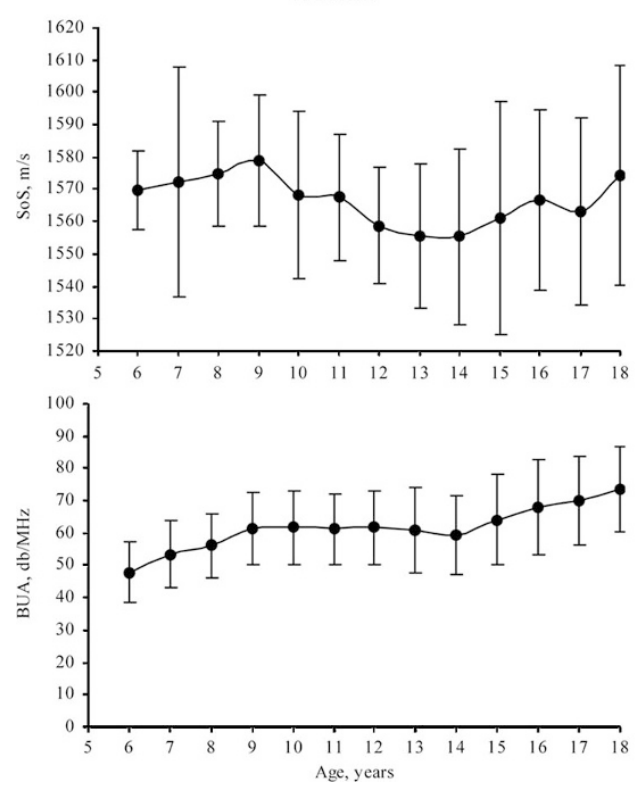
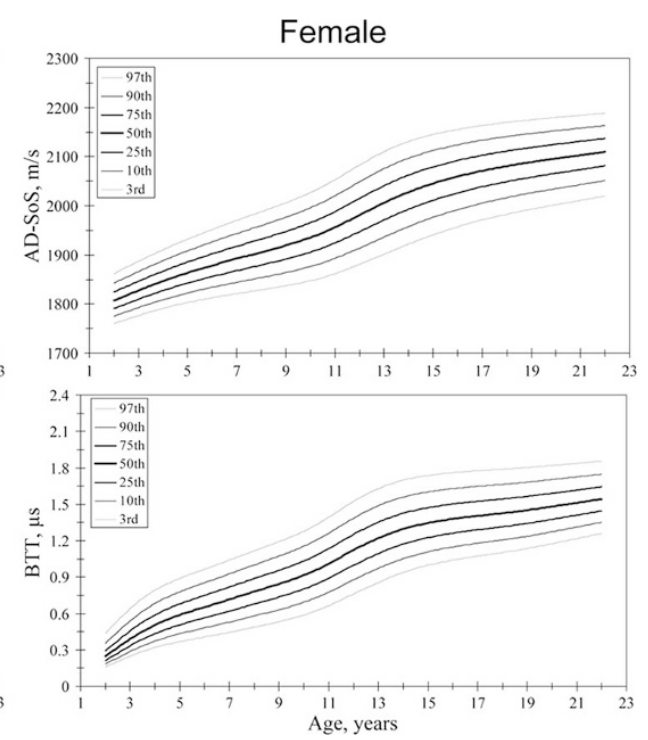

Female
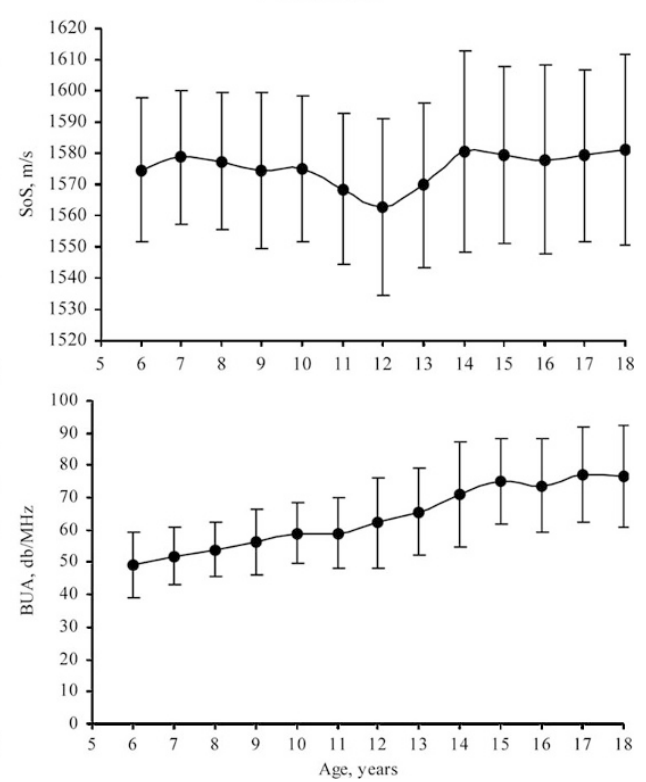

Figure 4. Static distance curves for ADSoS and BTT measured at the distal end of the proximal phalangeal diaphysis of the hand (DBM Sonic, IGEA, Carpi, Italy) in healthy male $(n=1513)$ and female $(n=$ 1531) subjects, expressed as centiles ( 97 th to 3rd). Figure reproduced from Baroncelli et al., Bone 39:159-173. Copyright (c) 2006 Elsevier Inc, with permission.

Figure 5. Values of SoS and BUA measured at the heel (Sahara, Hologic Inc., Waitham, MA) in healthy male $(n=1676)$ and female $(n=1623)$ subjects, expressed as mean $\pm \mathrm{SD}$. In both sexes, the peripubertal drop of SoS was not significant ( $p=$ NS). 

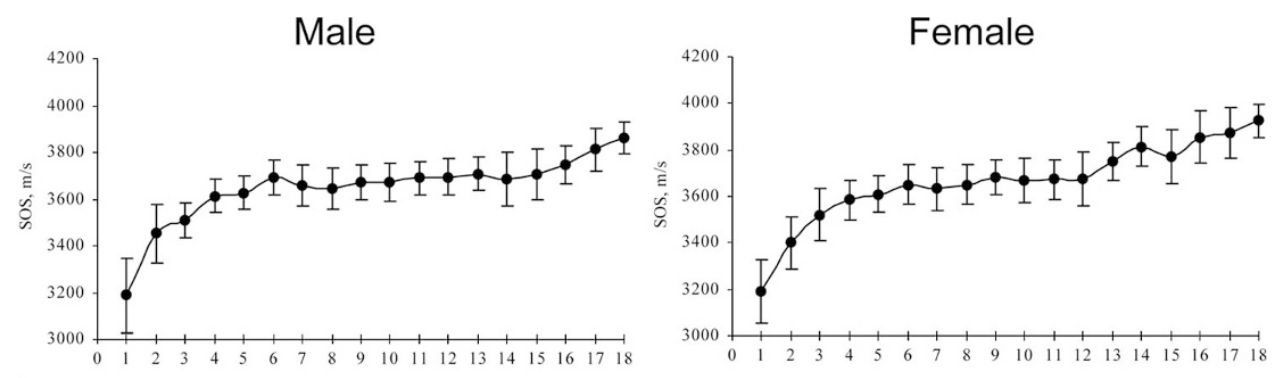

Figure 6. Values of $\operatorname{SoS}$ measured at tibia (midshaft, upper panels) and radius (distal third, lower panels) by Sunlight Omnisense 7000P (Tel Aviv, Israel) in healthy male (tibia, $n=485$; radius, $n=$ 447) and female (tibia, $n=590$; radius, $n=$ $544)$ subjects, expressed as mean \pm SD.
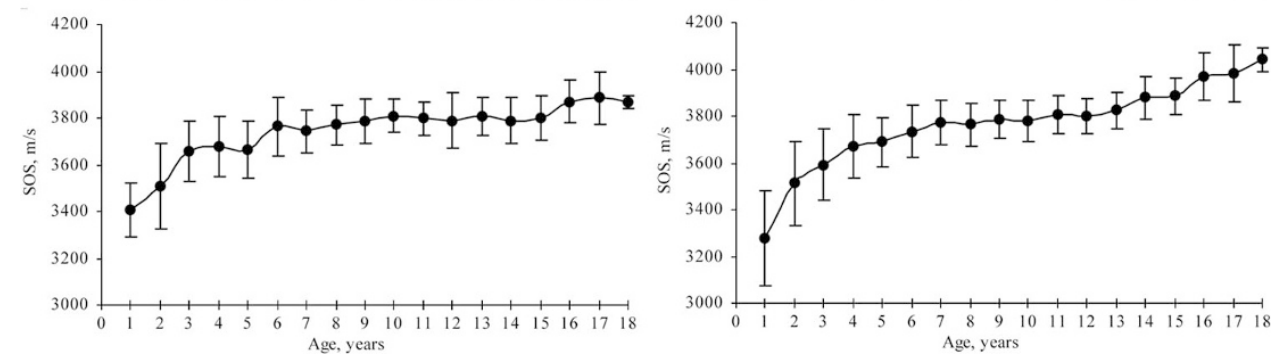

Distance curves for QUS variables may be a useful tool to assess the position of an individual in comparison with a reference population and to examine the trajectory of the examined QUS parameter in longitudinal measurements (16). Moreover, the possibility to calculate the Z-score for QUS variables according to the main anthropometric findings has an important clinical impact for estimating the degree of reduction of bone mineral status. Indeed, $Z$-score is the more appropriate method to express bone mineral status in children $(1,4,55)$, and a value, for each QUS variable, below -2.0 $Z$-score could identify a condition of "low bone mineral status" according to the anthropometric variable considered, as suggested for DXA measurements by the International Society for Clinical Densitometry (55).

\section{QUS MEASUREMENT IN PATIENTS WITH BONE AND MINERAL DISORDERS AND ASSESSMENT OF FRACTURE RISK}

Some studies demonstrated that a reduced value of a QUS variable, both velocity- and attenuation-based, is associated with a reduced bone mineral status in children with disturbances of growth or disorders affecting bone health (Table 2, 56-75). QUS and DXA parameters, measured at different skeletal sites, showed similar results, suggesting that both methods are able to identify a reduced bone mineral status.

Furthermore, it has been shown that in an otherwise healthy pediatric population $(76,77)$, and in children with bone and mineral disorders or chronic diseases $(30,60)$, QUS measurements detected a reduced bone mineral status in children suffering fractures. Fielding et al. (60), by calcaneal QUS, demonstrated that a value of BUA $Z$-score $<-2$ proved to be as sensitive as a spinal BMD Z-score $<-2$ in identifying children with prior low-impact fractures. Similar data were found by Baroncelli et al. (30) measuring AD-SoS at phalanges of the hand and spinal BMD and BMD volume by DXA. Moreover, Hartman et al. (42) in severely handicapped institutionalized children and adolescents found that tibia SoS Z-scores correlated negatively with the presence of past fracture.
These results suggest that in children QUS devices could be used to a similar extent as measurement by DXA to estimate bone mineral status and bone fragility, but current data are not sufficient to establish which of them is the best choice. Indeed, QUS and DXA do not measure identical properties of bone tissue, so that they do not capture the same patients. It should be considered that QUS parameters are influenced not only by bone density as occurs for DXA, but also by bone structure and composition, so that they give additional information, compared with DXA, on some aspect regarding bone quality $(7,8,10)$. In fact, some QUS parameters are able to detect collagen and organic matrix abnormalities in vitro $(76,78)$ and in vivo (79), giving some information on the organic components of bone material. Anyway, there are too few data linking bone mineral status by DXA, pQCT, or QUS measure to fracture rate in children, and further studies in a large number of subjects are needed to investigate this crucial aspect.

Some authors raised the question that QUS methods have major limitations in that these techniques do not analyze bone mass, density, and geometry separately (6) giving only an integral estimation of bone mineral status, as occurs for DXA (4-6). Although QUS variables yield many data that, at present, may be difficult to interpret, they are always linked with the properties of bone tissue, and reduced values of the QUS variables are related to a reduced bone mineral status and are able to identify a population of children with an increased risk of fractures. The actual position of QUS methods in the diagnosis of a reduced bone mineral status in children should be considered similar to that of DXA, and QUS measurements may be a viable initial screen for assessing bone mineral status in children.

Furthermore, preliminary studies suggested that some QUS methods might be a useful tool for assessing bone mineral status and skeletal development in term and preterm infants (80). This is not an argument of the present review that is limited only to QUS measurement in children. At any rate, the results are very encouraging for a future clinical use of some QUS methods in term and preterm newborns. 
Table 2. Summary of some QUS studies, some of these also reporting DXA measurements, in children with disturbances of growth or disorders affecting bone health

\begin{tabular}{|c|c|c|c|c|c|c|}
\hline Disease/disorder & $n$ & Skeletal site of measurement & QUS device & QUS variables & DXA variables & Reference \\
\hline $\begin{array}{l}\text { Bone and mineral } \\
\text { disorders }\end{array}$ & 135 & $\begin{array}{l}\text { Proximal phalanges of } \\
\text { the hand }\end{array}$ & $\begin{array}{l}\text { DBM Sonic 1200, } \\
\text { IGEA, Carpi, Italy }\end{array}$ & $\mathrm{AD}-\mathrm{SoS} \downarrow$ & $\begin{array}{l}\text { L-BMD } \downarrow \\
\text { L-vBMD } \downarrow\end{array}$ & 30 \\
\hline Genetic disorders & 50 & $\begin{array}{l}\text { Proximal phalanges of } \\
\text { the hand }\end{array}$ & $\begin{array}{l}\text { DBM Sonic } 1200, \\
\text { IGEA, Carpi, Italy }\end{array}$ & AD-SoS $\downarrow$ & - & 56 \\
\hline $\begin{array}{l}\text { Chronic rheumatic } \\
\text { diseases }\end{array}$ & 53 & Heel & $\begin{array}{l}\text { Cuba McCue, Ultrasonics } \\
\text { Compton, Winchester, UK }\end{array}$ & BUA $\downarrow$ & L-BMD $\downarrow$ & 57 \\
\hline $\begin{array}{l}\text { Chronic rheumatic } \\
\text { diseases }\end{array}$ & 40 & $\begin{array}{l}\text { Tibia midshaft, Radius } \\
\text { distal third }\end{array}$ & $\begin{array}{l}\text { Omnisense 7000S, Sunlight, } \\
\text { Tel Aviv, Israel }\end{array}$ & SoS $\downarrow$ & L-BMD $\downarrow$ & 58 \\
\hline $\begin{array}{l}\text { Juvenile idiopathic } \\
\text { arthritis }\end{array}$ & 70 & Heel & $\begin{array}{l}\text { Cuba McCue, Ultrasonics } \\
\text { Compton, Winchester, UK }\end{array}$ & $\begin{array}{l}\text { SoS } \downarrow \\
\text { BUA } \downarrow\end{array}$ & - & 59 \\
\hline $\begin{array}{l}\text { Chronic diseases and/or } \\
\text { fragility fractures }\end{array}$ & 42 & Heel & $\begin{array}{l}\text { Achilles Plus. Lunar Co, } \\
\text { Madison, WI, USA }\end{array}$ & $\begin{array}{l}\text { SoS } \downarrow \\
\text { BUA } \downarrow\end{array}$ & $\begin{array}{l}\text { TB-BMD } \downarrow \\
\text { L-F-BMD } \downarrow \\
\text { L-F-vBMD } \downarrow\end{array}$ & 60 \\
\hline $\begin{array}{l}\text { Inflammatory bowel } \\
\text { disease }\end{array}$ & 10 & Heel & $\begin{array}{l}\text { Cuba McCue, Ultrasonics } \\
\text { Compton, Winchester, UK }\end{array}$ & $\begin{array}{l}\text { SoS } \downarrow \\
\text { BUA } \downarrow\end{array}$ & - & 61 \\
\hline Crohn disease & 35 & $\begin{array}{l}\text { Tibia midshaft, Radius } \\
\text { distal third }\end{array}$ & $\begin{array}{l}\text { Sunlight Omnisense, Sunlight, } \\
\text { Tel Aviv, Israel }\end{array}$ & $\operatorname{SoS} \downarrow *$ & L-BMD $\downarrow$ & 62 \\
\hline Celiac disease & 41 & $\begin{array}{l}\text { Tibia midshaft, Radius } \\
\text { distal third }\end{array}$ & $\begin{array}{l}\text { Omnisense 7000P, Sunlight, } \\
\text { Tel Aviv, Israel }\end{array}$ & SoS $\downarrow$ & L-BMD $\downarrow$ & 63 \\
\hline End-stage renal failure & 30 & $\begin{array}{l}\text { Proximal phalanges of } \\
\text { the hand }\end{array}$ & $\begin{array}{l}\text { DBM Sonic } 1200 \text {, } \\
\text { IGEA, Carpi, Italy }\end{array}$ & $\mathrm{AD}-\mathrm{SoS} \downarrow$ & TB-L-BMD $\downarrow$ & 29 \\
\hline $\begin{array}{l}\text { Severely handicapped } \\
\text { institutionalized }\end{array}$ & 87 & $\begin{array}{l}\text { Tibia midshaft, Radius } \\
\text { distal third }\end{array}$ & $\begin{array}{l}\text { Omnisense 7000S, Sunlight, } \\
\text { Tel Aviv, Israel }\end{array}$ & SoS $\downarrow$ & - & 42 \\
\hline Severe cerebral palsy & 67 & Heel & $\begin{array}{l}\text { Sahara, Hologic Inc, } \\
\text { Waitham, MA, USA }\end{array}$ & QUI $\downarrow$ & - & 64 \\
\hline $\begin{array}{l}\text { Acute lymphoblastic } \\
\text { leukemia }\end{array}$ & 54 & $\begin{array}{l}\text { Proximal phalanges of } \\
\text { the hand }\end{array}$ & $\begin{array}{l}\text { DBM Sonic 1200, IGEA, } \\
\text { Carpi, Italy }\end{array}$ & AD-SoS N & - & 65 \\
\hline $\begin{array}{l}\text { Acute lymphoblastic } \\
\text { leukemia }\end{array}$ & 37 & Tibia midshaft & $\begin{array}{l}\text { SoundScan Compact, Myriad } \\
\text { Ultrasound System, } \\
\text { Rehovot, Israel }\end{array}$ & SoS $\downarrow$ & - & 66 \\
\hline $\begin{array}{l}\text { Acute lymphoblastic } \\
\text { leukemia }\end{array}$ & 42 & Heel & $\begin{array}{l}\text { QUS-2, Quidel, } \\
\text { San Diego, CA, USA }\end{array}$ & BUA $\downarrow$ & $\begin{array}{l}\text { TB-BMD } \downarrow \\
\text { L-BMD } \downarrow\end{array}$ & 67 \\
\hline Sickle cell disease & 80 & Heel & $\begin{array}{l}\text { Achilles Plus, Lunar Co, } \\
\text { Madison, WI, USA }\end{array}$ & $\begin{array}{l}\text { SoS } \downarrow \dagger \\
\text { BUA } \downarrow\end{array}$ & - & 68 \\
\hline HIV-infected & 44 & Heel & $\begin{array}{l}\text { Cuba McCue, Ultrasonics Compton, } \\
\text { Winchester, UK }\end{array}$ & BUA $\downarrow$ & - & 69 \\
\hline HIV-infected & 44 & $\begin{array}{l}\text { Proximal phalanges of } \\
\text { the hand }\end{array}$ & $\begin{array}{l}\text { DBM Sonic BP, } \\
\text { IGEA, Carpi, Italy }\end{array}$ & $\begin{array}{l}\text { AD-SoS } \downarrow \\
\text { BTT } \downarrow\end{array}$ & - & 70 \\
\hline $\begin{array}{l}\text { Central precocious } \\
\text { puberty, idiopathic } \\
\text { short stature after } \\
\text { Gn-RH agonist } \\
\text { treatment }\end{array}$ & 25 & Heel & UBIS 3000, DMS, Montpellier, France & $\begin{array}{l}\text { SoS N } \\
\text { BUA } \downarrow \neq\end{array}$ & $\begin{array}{l}\text { L-BMD } \downarrow \neq \\
\text { L-vBMD N }\end{array}$ & 71 \\
\hline Delayed puberty & 45 & $\begin{array}{l}\text { Tibia midshaft, Radius } \\
\text { distal third }\end{array}$ & $\begin{array}{l}\text { Omnisense 7000P, Sunlight, } \\
\text { Tel Aviv, Israel }\end{array}$ & SoS $\downarrow$ & - & 72 \\
\hline $\begin{array}{l}\text { Isolated growth } \\
\text { hormone deficiency }\end{array}$ & 68 & $\begin{array}{l}\text { Proximal phalanges of } \\
\text { the hand }\end{array}$ & $\begin{array}{l}\text { DBM Sonic } 1200, \\
\text { IGEA, Carpi, Italy }\end{array}$ & $\begin{array}{l}\text { AD-SoS } \downarrow \\
\text { BTT } \downarrow\end{array}$ & - & 73 \\
\hline $\begin{array}{l}\text { Insulin-dependent } \\
\text { diabetes mellitus }\end{array}$ & 30 & $\begin{array}{l}\text { Tibia midshaft, Radius } \\
\text { distal third }\end{array}$ & $\begin{array}{l}\text { Omnisense } 7000 \mathrm{~S}, \\
\text { Sunlight, Tel Aviv, Israel }\end{array}$ & SoS $\downarrow$ & - & 74 \\
\hline $\begin{array}{l}\text { Insulin-dependent } \\
\text { diabetes mellitus }\end{array}$ & 86 & $\begin{array}{l}\text { Proximal phalanges of } \\
\text { the hand }\end{array}$ & $\begin{array}{l}\text { DBM Sonic 1200, } \\
\text { IGEA, Carpi, Italy }\end{array}$ & $\mathrm{AD}-\mathrm{SoS} \downarrow$ & - & 75 \\
\hline
\end{tabular}

L indicates lumbar spine; F, femoral neck; TB, total body; N, normal values; $\downarrow$, reduced values; Gn-RH, gonadotrophin-releasing hormone; vBMD, volumetric bone mineral density.

* Only $19.2 \%$ of patients had a value $<-1$ Z-score.

$\dagger$ Only in male patients.

¥Only in children with idiopathic short stature.

\section{COMPARISON AMONG QUS METHODS, AND BETWEEN QUS METHODS AND DXA OR PQCT}

Few studies have shown comparison data between two or more skeletal sites by using the same or different QUS methods in children. Lequin et al. (81) showed a modest but significant correlation $(r=0.29, p<0.01)$ between calcaneal and tibial SoS, measured by two different QUS techniques. Schonau et al. (82), by using the same QUS device, found a good correlation between SoS measurements at the distal end of the proximal phalanx of the thumb and patella $(r=0.81$, 
$p<0.01$ ), whereas the correlation coefficients between thumb and patella against calcaneus were 0.48 and 0.40 , respectively. By using the same QUS device, a low $(r=0.39, p<0.02)$ (42) or a good correlation $(r=0.77, p<0.05)(62)$ between tibial (midshaft) and radial (distal third) SoS was reported. The different bone components at the ROI (Table 1) could explain, at least in part, these divergent results.

Studies in healthy children and in patients with disturbances of growth, disorders of bone and mineral metabolism, or chronic diseases have shown a wide range of correlation between QUS variables measured at the heel $(17,18,27,28,57,60,67)$, proximal phalanges of the hand $(29,30,83,84)$, midshaft tibia or distal third of the radius $(58,85)$ and central, peripheral, or total body BMD assessed by DXA. A mild correlation $(r=0.22)$ between calcaneal QUS and radial volumetric total BMD by pQCT was found (35).

These data confirm that QUS and DXA provide different information on bone tissue as they are influenced by different factors.

\section{CONCLUSIONS}

The growing knowledge on the physical mechanisms related to the ultrasound characterization of bone tissue and the clinical application of QUS methods have shown that these techniques are a useful tool to assess integral bone mineral status and fracture risk in children.

Although QUS devices are based on a similar technology, they differ among them for the skeletal site of measurement, performance, accuracy, measured QUS variables, and normative data. Large databases according to the main anthropometric findings from early childhood to young-adulthood are needed for a correct interpretation of the results in clinical setting.

The simplicity of use (that requires, however, an adequate training of the operators) of the QUS devices, the lack of radiation exposure for the child, the possibility to perform the examination at bedside, and the low cost represents clear advantages of QUS methods compared with x-ray-based densitometric techniques, as DXA and pQCT. However, too few comparative data on the estimation of fracture risk by using these methods are available in children to define which is the best among them for this purpose.

\section{REFERENCES}

1. Baroncelli GI, Bertelloni S, Sodini F, Saggese G 2005 Osteoporosis in children and adolescents: etiology and management. Paediatr Drugs 7:295-323

2. Njeh CF, Fuerst T, Hans D, Blake GM, Genant HK 1999 Radiation exposure in bone mineral density assessment. Appl Radiat Isot 50:215-236

3. Baroncelli GI, Saggese G 2000 Critical ages and stages of puberty in the accumulation of spinal and femoral bone mass: the validity of bone mass measurements. Horm Res 54:2-8

4. Fewtrell MS; British Paediatric \& Adolescent Bone Group 2003 Bone densitometry in children assessed by dual x ray absorptiometry: uses and pitfalls. Arch Dis Child 88:795-798

5. van Rijn RR, van der Sluis IM, Link TM, Grampp S, Guglielmi G, Imhof H, Gluer C, Adams JE, van Kuijk C 2003 Bone densitometry in children: a critical appraisal. Eur Radiol 13:700-710

6. Specker BL, Schoenau E 2005 Quantitative bone analysis in children: current methods and recommendations. J Pediatr 146:726-731

7. Genant HK, Engelke K, Fuerst T, Gluer C-C, Grampp S, Harris ST, Jergas M, Lang T, Lu Y, Majumdar S, Mathur A, Takada M 1996 Noninvasive assessment of bone mineral and structure: state of the art. J Bone Miner Res 11:707-730
8. Njeh CF, Boivin CM, Langton CM 1997 The role of ultrasound in the assessment of osteoporosis: a review. Osteoporos Int 7:7-22

9. Gregg EW, Kriska AM, Salamone LM, Roberts MM, Anderson SJ, Ferrell RE, Kuller LH, Cauley JA 1997 The epidemiology of quantitative ultrasound: a review of the relationship with bone mass, osteoporosis and fracture risk. Osteoporos Int 7:89-99

10. Kaufman JJ, Einhorn TA 1993 Perspective: ultrasound assessment of bone. J Bone Miner Res 8:517-525

11. Njeh CF, Fuerst T, Diessel E, Genant HK 2001 Is quantitative ultrasound dependent on bone structure? A reflection. Osteoporos Int 12:1-15

12. Hans D, Wu CY, Njeh CF, Zhao S, Augat P, Newitt D, Link T, Lu Y, Majumdar S, Genant HK 1999 Ultrasound velocity of trabecular cubes reflects mainly bone density and elasticity. Calcif Tissue Int 64:18-23

13. De Terlizzi F, Battista S, Cavani F, Canè V, Cadossi R 2000 Influence of bone tissue density and elasticity on ultrasound propagation: an in vitro study. J Bone Miner Res $15: 2458-2466$

14. Barkmann R, Rohrschneider W, Vierling M, Troger J, De Terlizzi F, Cadossi R, Heller M, Gluer C-C 2002 German pediatric reference data for quantitative transverse transmission ultrasound of finger phalanges. Osteoporos Int 13:55-61

15. Cadossi R, Canè V 1996 Pathways of transmission of ultrasound energy through the distal metaphysis of the second phalanx of pigs: an in vitro study. Osteoporos Int 6:196-206

16. Baroncelli GI, Federico G, Vignolo M, Valerio G, del Puente A, Maghnie M, Baserga M, Farello G, Saggese G; and The Phalangeal Quantitative Ultrasound Group 2006 Cross-sectional reference data for phalangeal quantitative ultrasound from early childhood to young-adulthood according to gender, age, skeletal growth, and pubertal development. Bone 39:159-173

17. Jaworski M, Lebiedowski M, Lorenc RS, Trempe J 1995 Ultrasound bone measurement in pediatric subjects. Calcif Tissue Int 56:368-371

18. Sundberg M, Gardsell P, Johnell O, Ornstein E, Sernbo I 1998 Comparison of quantitative ultrasound measurements in calcaneus with DXA and SXA at other skeletal sites: a population-based study on 280 children aged 11-16 years. Osteoporos Int 8:410-417

19. Magkos F, Manios Y, Babaroutsi E, Sidossis LS 2005 Quantitative ultrasound calcaneus measurements: normative data for the Greek population. Osteoporos Int 16:280-288

20. Wuster C, Albanese C, De Aloysio D, Duboeuf F, Gambacciani M, Gonnelli S, Gluer C-C, Hans D, Joly J, Reginster JY, De Terlizzi F, Cadossi R 2000 Phalangeal osteosonogrammetry study: age-related changes, diagnostic sensitivity, and discrimination power. The Phalangeal Osteosonogrammetry Study Group. J Bone Miner Res 15:1603-1614

21. Montagnani A, Gonnelli S, Cepollaro C, Bruni D, Franci MB, Lucani B, Gennari C 2002 Graphic trace analysis of ultrasound at the phalanges may differentiate between subjects with primary hyperparathyroidism and with osteoporosis: a pilot study. Osteoporos Int 13:222-227

22. Baroncelli GI, Federico G, Bertelloni S, de Terlizzi F, Cadossi R, Saggese G 2001 Bone quality assessment by quantitative ultrasound of proximal phalanxes of the hand in healthy subjects aged 3-21 years. Pediatr Res 49:713-718

23. Lequin MH, van Rijn RR, Robben SG, Hop WC, Dijkhuis S, Fijten MM, Meijer LA van Kuijk C 1999 Evaluation of short-term precision for tibial ultrasonometry. Calcif Tissue Int 64:24-27

24. Barkmann R, Kantorovich E, Singal C, Hans D, Genant HK, Heller M, Gluer CC 2000 A new method for quantitative ultrasound measurements at multiple skeletal sites: first results of precision and fracture discrimination. J Clin Densitom 3:1-7

25. van den Bergh JP, Noordam C, Ozyilmaz A, Hermus AR, Smals AG, Otten BJ 2000 Calcaneal ultrasound imaging in healthy children and adolescents: relation of the ultrasound parameters BUA and SOS to age, body weight, height, foot dimensions and pubertal stage. Osteoporos Int 11:967-976

26. Sawyer A, Moore S, Fielding KT, Nix DA, Kiratli J, Bachrach LK 2001 Calcaneus ultrasound measurements in a convenience sample of healthy youth. J Clin Densitom 4:111-120

27. Brukx LJ, Waelkens JJ 2003 Evaluation of the usefulness of a quantitative ultrasound device in screening of bone mineral density in children. Ann Hum Biol 30:304-315

28. Lum CK, Wang MC, Moore E, Wilson DM, Marcus R, Bachrach LK 1999 A comparison of calcaneus ultrasound and dual X-ray absorptiometry in healthy North American youths and young adults. J Clin Densitom 2:403-411

29. Pluskiewicz W, Adamczyk P, Drozdzowska B, Szprynger K, Szczepanska M, Halaba Z, Karasek D 2002 Skeletal status in children, adolescents and young adults with end-stage renal failure treated with hemo- or peritoneal dialysis. Osteoporos Int 13:353-357

30. Baroncelli GI, Federico G, Bertelloni S, Sodini F, De Terlizzi F, Cadossi R, Saggese G 2003 Assessment of bone quality by quantitative ultrasound of proximal phalanges of the hand and fracture rate in children and adolescents with bone and mineral disorders. Pediatr Res 54:125-136

31. Lin JC, Amling M, Newitt DC, Selby K, Srivastav SK, Delling G, Genant HK, Majumdar S 1998 Heterogeneity of trabecular bone structure in the calcaneus using magnetic resonance imaging. Osteoporos Int 8:16-24

32. van den Bergh JP, Noordam C, Thijssen JM, Otten BJ, Smals AG, Hermus AR 2001 Measuring skeletal changes with calcaneal ultrasound imaging in healthy children and adults: the influence of size and location of the region of interest. Osteoporos Int 12:970-979

33. Cheng S, Njeh CF, Fan B, Cheng X, Hans D, Wang L, Fuerst T, Genant HK 2002 Influence of region of interest and bone size on calcaneal BMD: implications for the accuracy of quantitative ultrasound assessments at the calcaneus. Br J Radiol 75:59-68

34. Kaga M, Takahashi K, Suzuki H, Matsueda M, Moriwake T, Miyatake N, Makino $\mathrm{H}$, Seino Y 2002 Ultrasound assessment of tibial cortical bone acquisition in Japanese children and adolescents. J Bone Miner Metab 20:111-115 
35. Fricke O, Tutlewski B, Schwahn B, Schoenau E 2005 Speed of sound: relation to geometric characteristics of bone in children, adolescents, and adults. J Pediatr 146:764-768

36. Guglielmi G, Njeh CF, de Terlizzi F, De Serio DA, Scillitani A, Cammisa M, Fan B, Lu Y, Genant HK 2003 Phalangeal quantitative ultrasound, phalangeal morphometric variables, and vertebral fracture discrimination. Calcif Tissue Int 72:469-477

37. Sakata S, Barkmann R, Lochmuller EM, Heller M, Gluer CC 2004 Assessing bone status beyond BMD: evaluation of bone geometry and porosity by quantitative ultrasound of human finger phalanges. J Bone Miner Res 19:924-930

38. Wuster C, de Terlizzi F, Becker S, Cadossi M, Cadossi R, Muller R 2005 Usefulness of quantitative ultrasound in evaluating structural and mechanical properties of bone: comparison of ultrasound, dual-energy X-ray absorptiometry, micro-computed tomography, and mechanical testing of human phalanges in vitro. Technol Health Care 13:497-510

39. Prevrhal S, Fuerst T, Fan B, Njeh C, Hans D, Uffmann M, Srivastav S, Genant HK 2001 Quantitative ultrasound of the tibia depends on both cortical density and thickness. Osteoporos Int 12:28-34

40. Sievanen H, Cheng S, Ollikainen S, Uusi-Rasi K 2001 Ultrasound velocity and cortical bone characteristics in vivo. Osteoporos Int 12:399-405

41. Chappard C, Camus E, Lefebvre F, Guillot G, Bittoun J, Berger G, Laugier PJ 2000 Evaluation of error bounds on calcaneal speed of sound caused by surrounding soft tissue. J Clin Densitom 3:121-131

42. Hartman C, Brik R, Tamir A, Merrick J, Shamir R 2004 Bone quantitative ultrasound and nutritional status in severely handicapped institutionalized children and adolescents. Clin Nutr 23:89-98

43. Cvijetic S, Baric IC, Bolanca S, Juresa V, Ozegovic DD 2003 Ultrasound bone measurement in children and adolescents. Correlation with nutrition, puberty, anthropometry, and physical activity. J Clin Epidemiol 56:591-597

44. Dib L, Arabi A, Maalouf J, Nabulsi M, El-Hajj Fuleihan G 2005 Impact of anthropometric, lifestyle, and body composition variables on ultrasound measurements in school children. Bone 36:736-742

45. Vignolo M, Parodi A, Mascagni A, Torrisi C, De Terlizzi F, Aicardi G 2006 Longitudinal assessment of bone quality by quantitative ultrasonography in children and adolescents. Ultrasound Med Biol 32:1003-1010

46. Zadik Z, Price D, Diamond G 2003 Pediatric reference curves for multi-site quantitative ultrasound and its modulators. Osteoporos Int 14:857-862

47. Pettinato AA, Loud KJ, Bristol SK, Feldman HA, Gordon CM 2006 Effects of nutrition, puberty, and gender on bone ultrasound measurements in adolescents and young adults. J Adolesc Health 39:828-834

48. Bayer M, Kutilek S 1997 Ultrasound transmission through the os calcis in children: which side should we measure? Calcif Tissue Int 61:441-442

49. Magkos F, Manios Y, Babaroutsi E, Sidossis LS 2005 Contralateral differences in quantitative ultrasound of the heel: the importance of side in clinical practice. Osteoporos Int 16:879-886

50. Mughal MZ, Ward K, Qayyum N, Langton CM 1997 Assessment of bone status using the contact ultrasound bone analyser. Arch Dis Child 76:535-536

51. Wunsche K, Wunsche B, Fahnrich H, Mentzel HJ, Vogt S, Abendroth K, Kaiser WA 2000 Ultrasound bone densitometry of the os calcis in children and adolescents. Calcif Tissue Int 67:349-355

52. Zhu ZQ, Liu W, Xu CL, Han SM, Zu SY, Zhu GJ 2007 Ultrasound bone densitometry of the calcaneus in healthy Chinese children and adolescents. Osteoporos Int 18:533-541

53. Halaba ZP, Pluskiewicz W 2004 Quantitative ultrasound in the assessment of skeletal status in children and adolescents. Ultrasound Med Biol 30:239-243

54. Lequin MH, van Rijn RR, Robben SG, Hop WC, van Kuijk C 2000 Normal values for tibial quantitative ultrasonometry in caucasian children and adolescents (aged 6 to 19 years). Calcif Tissue Int 67:101-105

55. Lewiecki EM, Watts NB, McClung MR, Petak SM, Bachrach LK, Shepherd JA, Downs RW Jr 2004 International Society for Clinical Densitometry Official positions of the international society for clinical densitometry. J Clin Endocrinol Metab 89:3651-3655

56. Pluskiewicz W, Pyrkosz A, Drozdzowska B, Halaba Z 2003 Quantitative ultrasound of the hand phalanges in patients with genetic disorders: a pilot case-control study. Osteoporos Int 14:787-792

57. Falcini F, Bindi G, Ermini M, Galluzzi F, Poggi G, Rossi S, Masi L, Cimaz R, Brandi ML 2000 Comparison of quantitative calcaneal ultrasound and dual energy $\mathrm{X}$-ray absorptiometry in the evaluation of osteoporotic risk in children with chronic rheumatic diseases. Calcif Tissue Int 67:19-23

58. Hartman C, Shamir R, Eshach-Adiv O, Iosilevsky G, Brik R 2004 Assessment of osteoporosis by quantitative ultrasound versus dual energy X-ray absorptiometry in children with chronic rheumatic diseases. J Rheumatol 31:981-985

59. Kutilek S, Bayer M, Dolezalova P, Nemcova D 2006 Quantitative ultrasonometry of the calcaneus in children with juvenile idiopathic arthritis. Rheumatology (Oxford) 45:1273-1275

60. Fielding KT, Nix DA, Bachrach LK 2003 Comparison of calcaneus ultrasound and dual X-ray absorptiometry in children at risk of osteopenia. J Clin Densitom 6:7-15

61. Kutilek S, Bayer M, Fruhauf P 2001 Growth failure and decreased ultrasound parameters of bone density in children with inflammatory bowel disease. Nutrition 17:83
62. Levine A, Mishna L, Ballin A, Givoni S, Dinari G, Hartman C, Shamir R 2002 Use of quantitative ultrasound to assess osteopenia in children with Crohn disease. J Pediatr Gastroenterol Nutr 35:169-172

63. Hartman C, Hino B, Lerner A, Eshach-Adiv O, Berkowitz D, Shaoul R, Pacht A, Rozenthal E, Tamir A, Shamaly H, Shamir R 2004 Bone quantitative ultrasound and bone mineral density in children with celiac disease. J Pediatr Gastroenterol Nutr 39:504-510

64. Jekovec-Vrhovsek M, Kocijancic A, Prezelj J 2005 Quantitative ultrasound of the calcaneus in children and young adults with severe cerebral palsy. Dev Med Child Neurol 47:696-698

65. Pluskiewicz W, Luszczynska A, Halaba Z, Drozdzowska B, Sonta-Jakimczyk D 2002 Skeletal status in survivors of childhood acute lymphoblastic leukemia assessed by quantitative ultrasound: a pilot cross-sectional study. Ultrasound Med Biol 28:1279-1284

66. Lequin MH, van der Sluis IM, van den Heuvel-Eibrink MM, Hop WJ, van Rijn RR, de Muinck Keizer-Schrama SF, van Kuijk C 2003 A longitudinal study using tibial ultrasonometry as a bone assessment technique in children with acute lymphoblastic leukaemia. Pediatr Radiol 33:162-167

67. Ahuja SP, Greenspan SL, Lin Y, Bowen A, Bartels D, Goyal RK 2006 A pilot study of heel ultrasound to screen for low bone mass in children with leukemia. J Pediatr Hematol Oncol 28:427-432

68. VanderJagt DJ, Bonnett C, Okolo SN, Glew RH 2002 Assessment of the bone status of Nigerian children and adolescents with sickle cell disease using calcaneal ultrasound and serum markers of bone metabolism. Calcif Tissue Int 71:133-140

69. Stagi S, Bindi G, Galluzzi F, Galli L, Salti R, de Martino M 2004 Changed bone status in human immunodeficiency virus type 1 (HIV-1) perinatally infected children is related to low serum free IGF-I. Clin Endocrinol (Oxf) 61:692-699

70. Rosso R, Vignolo M, Parodi A, Di Biagio A, Sormani MP, Bassetti M, Aicardi G, Bassetti D 2005 Bone quality in perinatally HIV-infected children: role of age, sex, growth, HIV infection, and antiretroviral therapy. AIDS Res Hum Retroviruses 21:927-932

71. Kapteijns-van Kordelaar S, Noordam K, Otten B, van den Bergh J 2003 Quantitative calcaneal ultrasound parameters and bone mineral density at final height in girls treated with depot gonadotrophin-releasing hormone agonist for central precocious puberty or idiopathic short stature. Eur J Pediatr 162:776-780

72. Zadik Z, Sinai T, Borondukov E, Zung A, Yaniv I, Reifen R 2005 Longitudinal monitoring of bone accretion measured by quantitative multi-site ultrasound (QUS) of bones in patients with delayed puberty (a pilot study). Osteoporos Int 16:1036-1041

73. Vignolo M, Di Battista E, Parodi A, Torrisi C, De Terlizzi F, Aicardi G 2007 Bone quality assessed by phalangeal quantitative ultrasonography in children and adolescents with isolated idiopathic growth hormone deficiency. J Endocrinol Invest 30:445-450

74. Damilakis J, Galanakis E, Mamoulakis D, Sbyrakis S, Gourtsoyiannis N 2004 Quantitative ultrasound measurements in children and adolescents with: type 1 diabetes. Calcif Tissue Int 74:424-428

75. Valerio G, del Puente A, Buono P, Esposito A, Zanatta M, Mozzillo E, Moretto E, Mastidoro L, Franzese A 2004 Quantitative ultrasound of proximal phalanxes in patients with type 1 diabetes mellitus. Diabetes Res Clin Pract 64:161-166

76. Suuriniemi M, Mahonen A, Kovanen V, Alén M, Cheng S 2003 Relation of PvuII site polymorphism in the COL1A2 gene to the risk of fractures in prepubertal Finnish girls. Physiol Genomics 14:217-224

77. Schalamon J, Singer G, Schwantzer G, Nietosvaara Y 2004 Quantitative ultrasound assessment in children with fractures. J Bone Miner Res 19:1276-1279

78. Mehta SS, Oz OK, Antich PP 1998 Bone elasticity and ultrasound velocity are affected by subtle changes in the organic matrix. J Bone Miner Res 13:114-121

79. Cheng S, Tylavsky FA, Orwoll ES, Rho JY, Carbone LD 1999 The role of collagen abnormalities in ultrasound and densitometry assessment: in vivo evidence. Calcif Tissue Int 64:470-476

80. McDevitt H, Ahmed SF 2007 Quantitative ultrasound assessment of bone health in the neonate. Neonatology 91:2-11

81. Lequin MH, Hop WC, van Rijn RR, Bukkems MC, Verhaak LL, Robben SG, Van Kuijk C 2001 Comparison between quantitative calcaneal and tibial ultrasound in a Dutch Caucasian pediatric and adolescent population. J Clin Densitom 4:137-146

82. Schonau E, Radermacher A, Wentzlik U, Klein K, Michalk D 1994 The determination of ultrasound velocity in the os calcis, thumb and patella during childhood. Eur J Pediatr 153:252-256

83. Halaba ZP, Konstantynowicz J, Pluskiewicz W, Kaczmarski M, PiotrowskaJastrzebska J 2005 Comparison of phalangeal ultrasound and dual energy X-ray absorptiometry in healthy male and female adolescents. Ultrasound Med Biol 31:1617-1622

84. Pluskiewicz W, Adamczyk P, Drozdzowska B, Pyrkosz A, Halaba Z 2006 Quantitative ultrasound and peripheral bone densitometry in patients with genetic disorders. Ultrasound Med Biol 32:523-528

85. Njeh CF, Shaw N, Gardner-Medwin JM, Boivin CM, Southwood TR 2000 Use of quantitative ultrasound to assess bone status in children with juvenile idiopathic arthritis: a pilot study. J Clin Densitom 3:251-260 